ADIPOSITAS

\section{Je dichter der Verkehr, desto höher der BMI}

Forscher der University of Alberta haben einen Risikofaktor für Übergewicht ausgemacht, der bisher nicht berücksichtigt wurde. Ob Menschen einen höheren oder niedrigeren BMI haben, hängt auch von der Qualität der unmittelbaren Umgebung ihrer Wohnung ab. Wer in einem Stadtviertel wohnt, das optisch wenig Abwechslung bietet, in dem dichter Straßenverkehr herrscht und in dem es auf der Straße möglicherweise auch nicht sicher ist, hat einen höheren BMI als jemand der in einer attraktiven, sicheren Wohngegend mit vielen Geschäften wohnt.

Grund ist die körperliche Aktivität. Wer sich auf der Straße unwohl fühlt, bewegt sich auch weniger als jemand, der in einer attraktiven Wohngegend zu Hause ist. Bei jungen Menschen in schlechter Umgebung ist der Anstieg des BMI besonders ausgeprägt und bedrohlich, so die Forscher.

$\mathbf{R M}$ =

Pressemitteilung der University of Alberta, Faculty of Physical Education and Recreation

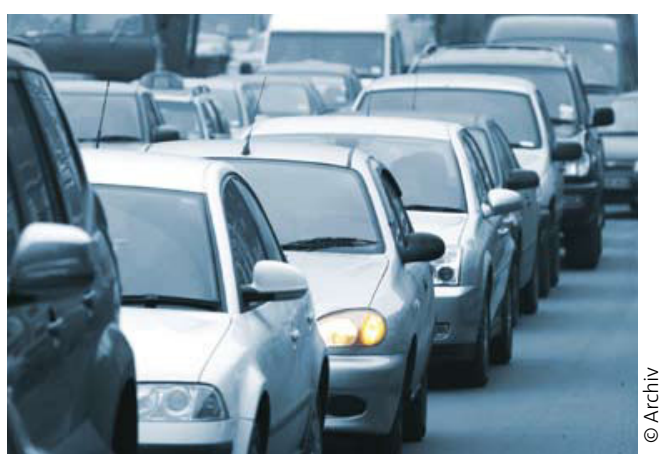

In der Umgebung solcher Autokolonnen drohen Übergewicht und Herzinfarkt.
US-KARDIOLOGEN WARNEN

Feinstaub verkürzt das Leben

Schon eine kurzfristige Feinstaubexposition über Stunden bis Wochen kann kardiovaskuläre Todesfälle sowie nicht tödliche Herz-Kreislauf-Erkrankungen auslösen, heißt es in einem aktuellen Bericht der American Heart Association (AHA). Besonders anfällig seien ältere Menschen und KHK-Patienten. Eine dauerhafte Feinstaubbelastung verkürzt nach Einschätzung der AHA die Lebenserwartung im Schnitt um einige Monate bis Jahre.

Die AHA empfiehlt, bei Risikopatienten mit starker Exposition die traditionellen kardiovaskulären Risikofaktoren besonders gut zu kontrollieren und die $\mathrm{Pa}$ tienten ggf. auch darüber zu beraten, wie sie ihre Feinstaubexposition reduzieren können. Aussagen zu Masken oder Feinstaubfiltern macht die AHA nicht. BS . Circulation 2010; doi: 10.1161/CIR.obo13e3181dbece1

\title{
Die Ehe: eine gesundheitsstiftende Einrichtung?
}

Ist die Ehe der Gesundheit förderlich - oder doch eher abträglich? Das Thema ist ebenso aktuell wie brisant und dies, seit es eine epidemiologische Forschung gibt. Schon die legendäre Framingham-Studie konnte zeigen, dass zwar nicht die Ehe als solche, jedoch die akademische Vorbildung der Ehefrau einen wichtigen Risikofaktor für den akuten Herztod des Ehemanns darstellt, noch gefährlicher als Hochdruck oder Rauchen. Es wird kolportiert, dass man dieses überraschende Ergebnis aus Gründen der politischen Korrektheit damals nicht publiziert habe. Aber nachvollziehbar ist es allemal, dass ein Heimchen am Herd, welches dem Mann den Rücken freihält für sein berufliches Fortkommen, weniger Stress verursacht als eine ebenso karriereorientierte Ehefrau.
Die Ehefrau als

Gesundheitspolizistin

In den letzten Jahren sind viele Studien erschienen, die der Ehe übereinstimmend eine lebensverlängernde Wirkung insbesondere für den Mann attestiert haben. Ein Erklärungsmodell beruft sich auf die Funktion der Ehefrau als Gesundheitspolizistin, wenn es um die Einhaltung von Arztterminen bzw. Diäten oder die regelmäßige Tabletteneinnahme geht. Für die KHK-Prävention wurde als These formuliert: Es ist nicht so entscheidend, ob Sie Butter essen, wichtiger ist vielmehr, ob Sie diese mit dem Ehepartner gemeinsam genießen.

\section{Vereint in die Demenz}

Jetzt werden wir plötzlich mit zwei neuen Studien konfrontiert, die das Dogma von der gesundmachenden
Ehe ins Wanken bringen. Danach besteht sowohl bei der Demenz als auch bei der chronischen Niereninsuffizienz ein hohes Risiko, dass es beide Eheleute gemeinsam,erwischt“. Doch was treibt Eheleute gemeinsam in den Wahnsinn oder an die Dialyse? Bei der Art der Erkrankungen, um die es hier geht, dürfte die Infektionshypothese wohl nicht greifen. Bleiben also nur die gemeinsamen Lebensbedingungen, egal was man darunter auch verstehen mag. Zyniker mögen anmerken, dass das „Ja-Wort“ bereits das Initialsymptom einer beginnenden Demenz sein könnte oder dass eine langjährige Ehe nur bei kognitiven Defiziten zu ertragen sei. Wie dem auch sei, es bleibt die Empfehlung: Heiraten ohne zu grübeln, ansonsten ist die Ehe nicht zu ertragen!

Dr. med. Peter Stiefelhagen 